\title{
Ear preference and abstractness in dichotic listening
}

\begin{abstract}
Abstraet
Right ear preference in terms of percentage correct and number of ear orders was demonstrated in a dichotic listening context using noun pairs matched for initial phonemes. Ear order effects were markedly reduced as compared with previous results. The superiority of right over left ear was found in both immediate and delayed orders of reporting.

Concrete words were reported more often than abstract words in both immediate and delayed channels. Parallel presentation (concrete and abstract words on separate channels) increased the probability of ear order effects.
\end{abstract}

\section{Introduction}

An individual listening to different sets of digits presented simultaneously to the two ears tends to report all the numbers from one ear (immediate channel) before reporting those from the other (delayed channel) (Bryden, 1962)。Evidence suggests that the right ear is preferred as the immediate channel (Bryden, 1963) and is more efficient than the left when employed as the delayed channel (ear asymmetry) (Satz, Achenbach, Pattishall, \& Fennell, 1965).

While most earlier studies employed digits, Yntema \& Trask (1963) and Bryden (1964) have used words in producing ear order effects. Emmerich, Goldenbaum, Hayden, Hoffman, \& Treffts (1965) have shown that ear order is dependent, in part, upon the meaningfulness of interpair word associations.

The present study investigates ear order and ear asymmetry effects with pairs of nouns and analyzes the roles of word abstractness in dichotic listening.

\section{Method}

Twenty-four pairs of one-syllable nouns were chosen from the list of A-frequency words (Thorndike-Lorge, 1944) scaled as to meaningfulness (m), concreteness (c), and specificity (s) by Spreen \& Schulz (in press). Each pair of words consisted of a high and low abstract noun (HA and LA) with abstractness defined as the sum of $c$ and $s$. Mean abstractness ratings were 7.75 and 11.70 , respectively. The average $m$ values for the HA and LA words were not significantly different (8.19 and 8.37). Pairs were matched for initial phonemes since a previous study (Spreen, Borkowski, \& Benton, in press) showed that auditory word recognition is highly related to phonemic structure.

Simultaneous presentation was achieved as follows: Two recorders, each containing a tape-loop with a single word, were used to produce multiple recordings of each pair on a two-channel recorder. These pairs were replayed into a Schwarzer EOG and pairs with less than $15 \mathrm{msec}$. difference on the oscillogram were selected (average difference between onsets of pair-members was $7 \mathrm{msec}$.). Peak loudness level for each pair and within-sets was $60 \pm 2 \mathrm{db}$.

Eight sets of three pairs of words were presented on earphones with an interpair interval of $1 \mathrm{sec}$. and an interset interval of $20 \mathrm{sec}$. Half of the sets contained HA and LA words on separate sides (parallel presentation) while the other sets had LA, HA, LA words on one side and HA, LA, HA words on the other (crisscross presentation). An equal number of HA and LA words were presented on each channel.

Forty University of Iowa sophomores, without history of hearing difficulties, served as Ss. Before each set, Ss were told to report all the words presented to one ear before reporting those from the other, but to give as many words as possible. On half of the eight sets, Ss were told to report words from the right side first, on the other half words from the left side first, in counterbalanced sequence. Earphones were reversed for half of the Ss.

\section{Results}

Ear asymmetry. Overall recall was $51 \%$. Correct recall on the right ear was $54 \%$, on the left ear $48 \%$. The difference between performance on the two ears was significant in favor of the right side $(t(39)=2.43, p<.05)$. Twenty-seven of $40 \mathrm{Ss}$ reported more correct responses on the right than on the left ear ( $z$ corrected for continuity $=2.06, \mathrm{p}<.05$ ).

An inspection of Table I shows that the right ear had a greater number of correct recalls than the left in terms of both immediate and delayed channels $(t(39)=$ 2.29 and 1.96 respectively, $\mathrm{p}<.05$ ).

Strict ear-order separation (three successive recalls of immediate channel words). occurred on 51 of 320 sets $(16 \%), 18 \%$ on the right and $14 \%$ on the left ear. Using a less stringent definition of ear order (the first two successive recalls of immediate channel words), the effect occurred on 145 of 320 sets (45\%), $47 \%$ on the right ear and $43 \%$ on the left ear.

Abstractness. The percentage of correct recalls was significantly greater for LA than for HA words (55\% vs. $47 \% ; t(39)=3.06, p<.01$ ), with 27 of 40 Ss reporting more recalls for LA than for $H A$ words (corrected $z=2.06$, $(p<.05)$. An inspection of Table II indicates that the superiority of LA over HA words was maintained irrespective of "ear dominance" or order of reporting.

TABLE I Percentage of Correct Recalls as Related to Instructed Order of Reporting

\begin{tabular}{lcc} 
& Immediate Chaninel & Delay Channel \\
\hline Right ear & $63 \%$ & $46 \%$ \\
Left ear & $56 \%$ & $40 \%$ \\
\hline
\end{tabular}

TABLE II Percentage Correct of High (HA) and Low Abstract (LA) Words

\begin{tabular}{lrccc} 
& \multicolumn{2}{c}{ Immediate } & Channel & \multicolumn{2}{c}{ Delay Channel } \\
\hline Right ear & $67 \%$ & $58 \%$ & $50 \%$ & $44 \%$ \\
Left ear & $61 \%$ & $52 \%$ & $44 \%$ & $36 \%$ \\
\hline
\end{tabular}


The effect of abstractness on ear order is demonstrated by the fact that $56 \%$ of the total ear orders occurred with parallel and $44 \%$ with criss-cross presentation of HA and LA words. Of the ear orders given under parallel presentation, $66 \%$ occurred with LA words on the immediate channel.

\section{Discussion}

In contrast to the study of Bryden (1964), who found recall to be between $75 \%$ and $85 \%$ for monosyllabic words presented at a rate of 1 pair/sec,overall pr formance in the present study was $51 \%$. This may be a result of reduced discriminability due to phonemic matching of word pairs. A second possible consequence of using words matched for initial phonemes was to reduce the number of reported ear orders. In comparison with previous results (Satz et al, 1965) where the frequency of "strict" ear order effects was around 70\%, the present data show a less frequent ear order effect $(45 \%)$ even with less stringent criteria.

The generality of the right ear preference reported by Bryden (1962) is extended by the present data. The right channel was superior to the left both in terms of percentage correct and number of reported ear orders. This is in contrast to evidence presented by Satz et al (1965) who found a tendency for Ss to prefer the right channel as the delayed channel.

The superiority of right over left ear was found for both immediate and delayed orders of report. Thus the ear asymmetry effect, which Satz et al (1965) has shown for the delayed channel, is observed also in the immediate channel when monosyllabic words are used.

The six left-handers in the present study showed a preference for the right ear both in terms of percentage correct and number of ear orders. There was no evidence for an interaction between handedness and ear asymmetry as reported by Bryden (1965).

In support of data from Yntema \& Trask (1963), Bryden (1964), and Emmerich et al (1965), the present results show that word characteristics contribute to the occurrence of ear order effects. Parallel presentation of HA and LA words on separate channels appears to provide slightly better cues for the occurrence of ear order than crisscross presentation. In addition to word characteristics like abstractness, Bryden (1962) has suggested that ear order effects seem to be determined by temporal, spatial and associative relations between stimulus pairs.

Paivio (1965) has recently shown stimulus abstractness to be a significant variable in paired-associate learning. The presen, results indicate that abstractness, with $\mathrm{m}$ held constant, is also an important variable in dichotic recall. It is difficult to c end Paivio's (1965) "conceptual peg" hypothesis to explain the facilitating effects of concreteness in the dichotic context, though it is entirely possible that "imagery" may play an important role in many short-term storage situations.

\section{References}

Bryden, M. P. Order of report in dichotic listening. Canad. J. Psychol., 1962, 16, 291-299.

Bryden, M. P. Ear preference in auditory perception. J. exp. Psychol., 1963, 65, 103-105.

Bryden, M. P. The manipulation of strategies of report in dichotic listening. Canad. J. Psychol., 1964, 18, 126-138.

Bryden, M. P. Tachistoscopic recognition, handedness, and cerebral dominance. Neuropsychologia, 1965, 3, 1-8.

Emmerich, D. S., Goldenbaum, D.M., Hayden, D. L., Hoffman, L. S., \& Treffts, J. L. Meaningfulness as a variable in dichotic hearing. J. exp. Psychol., 1965, 69, 433-436.

Paivio, A. Abstractness, imagery, and meaningfulness in pairedassociate learning. J. verbal Learn. verbal Behav., 1965, 4, 32-38.

Satz, P., Achenbach, K., Pattishall, E., \& Fennell, E. Order of report, ear asymmetry, and handedness in dichotic listening. Cortex, 1965, 1, 377-396.

Spreen, O., \& Schulz, R. W. Parameters of abstraction, meaningfulness, and pronounciability for 329 nouns. J. verbal Learn. verbal Behav., in press.

Spreen, O., Borkowski, J. G., \& Benton, A. L. Auditory recognition in relation to meaningfulness, abstractness, and phonetic structure of words. J. verbal Learn. verbal Behav., in press.

Thorndike, E. L., \& Lorge, I. The teacher's word book of 30,000 words. New York: Columbia University Press, 1944.

Yntema, D. B., \& Trask, F. P. Recall as a search process. J. ierbal Learn. verbal Behav., 1963, 2, 65-74.

\section{Notes}

1. This study was supported by Program Project Grant NB-03354 and Research Grant NB-00616 from the National Institute of Neurological Diseases and Blindness. Neurosensory Center Publication No. 90. We are grateful to Donald P. Seelig for valuable assistance. 2. Now at Oberlin College. 